\title{
Impact of 24-h feed, water, or feed and water deprivation on feed intake, metabolic, and inflammatory responses in beef heifers
}

\author{
Rodrigo S. Marques, ${ }^{*, 1}$ David W. Bohnert, ${ }^{*}$ Osvaldo A. de Sousa, ${ }^{* \dagger}$ Alice P. Brandão, ${ }^{*,}$ \\ Thiago F. Schumaher, ${ }^{*} \dagger$ Kelsey M. Schubach, ${ }^{*}, *$ Marina P. Vilela,* Bruna Rett, ${ }^{* \dagger}$ and \\ Reinaldo F. Cooke ${ }^{\ddagger}$
}

*Eastern Oregon Agricultural Research Center - Oregon State University, Burns, OR 97720; 'School of Veterinary Medicine and Animal Science, São Paulo State University (UNESP), Botucatu 18168-000, Brazil; and ${ }^{\ddagger}$ Department of Animal Science, Texas A\&M University, College Station, TX 77845

\begin{abstract}
This experiment investigated the effects of 24-h feed or water deprivation on hay intake, metabolic, and inflammatory responses in growing beef heifers. Forty Angus $\times$ Hereford heifers were ranked by initial BW $(275 \pm 6 \mathrm{~kg})$ and age $(278 \pm 6 \mathrm{~d})$ and randomly allocated to 20 drylot pens ( 2 heifers/pen). Pens were randomly assigned to 1 of 5 squares $(4 \times 4 ; 4$ pens/square; a total of 8 animals per square), that were run simultaneously with each containing 4 experimental periods of 17 d each (day -6 to 10 ). From day -5 to 0 of each period, pens were offered alfalfa-grass hay ad libitum $+454 \mathrm{~g}$ of dried distillers grains with solubles (as-fed basis) per heifer daily. On day 0 of each period, pens received 1 of 4 treatments: 1) feed and water deprivation for $24 \mathrm{~h}$ (FWD), 2) feed deprivation for $24 \mathrm{~h}$, but regular access to water (FD), 3) water deprivation for $24 \mathrm{~h}$, but regular access to feed (WD), or 4) regular access to feed and water $(\mathbf{C O N})$. Treatments were concurrently applied from day 0 to 1 . Heifer full BW was collected on day -6 and -5 , before (day 0 ) and after (day 1) treatment application, and on day 3, 6, 9, and 10 of each period. Hay DMI was recorded daily from day -5
\end{abstract}

to 10 . Blood samples were collected on day $-5,0,1$, 3,6 , and 10 of each experimental period. Following treatment application on day 1, BW loss was greater, and BW was less $(P<0.01)$ in WD, FWD, and FD compared with CON heifers, and similar $(P=0.64)$ among FWD and FD heifers. No treatment effects were detected $(P \geq 0.21)$ for final BW and overall ADG. Plasma cortisol concentrations were greater $(P<0.01)$ in FD and FWD vs. WD and CON on day 1 , whereas $\mathrm{FD}$ had greater $(P<0.01)$ plasma cortisol concentration vs. CON, WD, and FWD on day 6 and 10. Serum NEFA concentration was greater $(P<0.01)$ in FD and FWD vs. WD and CON on day 1 , and greater $(P<0.01)$ in WD vs. CON heifers on day 1 . No treatment effects were detected $(P=0.53)$ for plasma haptoglobin concentration. Plasma ceruloplasmin concentration was greater $(P<0.01)$ in FD and FWD vs. CON on day 1 , and greater $(P<0.01)$ in FD vs. CON and WD on day 3 and 6. Collectively, feed or water deprivation for $24 \mathrm{~h}$ did not impact feed intake and BW gain, whereas metabolic results suggest that feed deprivation stimulates cortisol, NEFA, and ceruloplasmin responses in growing beef heifers.

Key words: beef heifers, cortisol, feed and water deprivation, hay intake, metabolic response

(C) The Author (s) 2018. Published by Oxford University Press on behalf of the American Society of Animal Science. All rights reserved. For permissions, please e-mail: journals.permissions@oup.com.

J. Anim. Sci. 2019.97:398-406 doi: 10.1093/jas/sky397

\section{INTRODUCTION}

${ }^{1}$ Corresponding author: marquesr@oregonstate.edu

Received August 27, 2018.

Accepted October 6, 2018.
Feed and water deprivation is common during routine management practices in beef cattle systems such as weaning (Haley et al., 2005), transportation (Marques et al., 2012), and feedlot 
receiving (Loerch and Fluharty, 1999). These management practices may induce inflammatory and acute-phase reactions that often lead to impaired cattle productivity and health (Cooke, 2017). For instance, feed and water deprivation during long transportation periods $(>24 \mathrm{~h}$ ) is a major contributor to the acute-phase response and reduced performance in receiving cattle (Marques et al., 2012). Additionally, fasting stimulates mobilization of body nutrients (Cooke et al., 2007) and a neuroendocrine stress response (Ward et al., 1992; Henricks et al., 1994), which also elicits acute-phase reactions in cattle (Cooke and Bohnert, 2011; Cooke et al., 2012). Feed and water deprivation may also disturb the ruminal flora and cause microbial death (Meiske et al., 1958), resulting in the release of microbial endotoxins which could trigger the acutephase response (Carroll et al., 2009). According to Galyean et al. (1981), the ruminal microbial population takes $72 \mathrm{~h}$ to return to its initial levels after feed and water deprivation events. This disrupt in the microbial population can decrease ruminal fermentative capacity (Cole et al., 1986) and feed intake (Cole and Hutcheson, 1985). Receiving cattle, which also experience long periods of feed and water deprivation, typically consume $0.5 \%$ to $1.5 \%$ of their BW during the first week, $1.5 \%$ to $2.5 \%$ of their BW in the second week, with normal intake $(2.5 \%$ to $3.5 \%)$ only being reached between the second to fourth week after feedlot arrival (Hutcheson and Cole, 1986). Water deprivation has been shown to have a negative impact on intake and BW by decreasing cattle meal size, presumably in an attempt to maintain rumen homeostasis during extended water withdrawal (Utley et al., 1970; Senn et al., 1996; Steiger Burgos et al., 2001).

The majority of research conducted to date within this subject, however, has focused on both feed and water deprivation, with little known about the potential impacts of either feed or water deprivation on feed intake, metabolic, and inflammatory responses in beef cattle. Given that, we hypothesized that feed or water deprivation would negatively impact performance, metabolic, and inflammatory responses in growing heifers. Therefore, the objective of this experiment was to compare the effects of 24-h feed, water, or feed and water deprivation on feed intake, metabolic, and inflammatory responses in growing beef heifers.

\section{MATERIALS AND METHODS}

This experiment was conducted at the Oregon State University - Eastern Oregon Agricultural
Research Center (Burns station). All animals were cared for in accordance with acceptable practices and experimental protocols reviewed and approved by the Oregon State University, Institutional Animal Care and Use Committee (\#5016).

\section{Animals and Treatments}

Forty Angus $\times$ Hereford crossbred heifers, weaned $60 \mathrm{~d}$ before the beginning of the experiment, were ranked by initial BW $(275 \pm 6 \mathrm{~kg})$ and age $(278 \pm 6 \mathrm{~d})$ and randomly allocated to 20 drylot pens ( 2 heifers/pen; $7 \times 15 \mathrm{~m})$. Pens were randomly assigned to 1 of 5 squares $(4 \times 4 ; 4$ pens/square; a total of 8 animals per square), that were run simultaneously with each containing 4 experimental periods of $17 \mathrm{~d}$ each (day -6 to 10 ). From day -5 to 0 of each period, all pens were offered alfalfa-grass hay ad libitum $+454 \mathrm{~g} /$ heifer daily of dried distillers grains with solubles (DDGS; as-fed basis), which was offered separately from hay in a different section of the same feed bunk. On day 0 of each period, pens received 1 of 4 treatments: 1) feed and water deprivation for $24 \mathrm{~h}$ (FWD), 2) feed deprivation for $24 \mathrm{~h}$, but regular access to water (FD), 3 ) water deprivation for $24 \mathrm{~h}$, but regular access to feed (WD), or 4) regular access to feed and water (CON). Treatments were concurrently applied from day 0 to day 1 . Upon completion of treatment application (day 1), all pens received the same diet offered before treatment application. During treatment application, mean, maximum, and minimum average temperatures $\left({ }^{\circ} \mathrm{C}\right)$ across periods were, respectively, $-1.5,4.0$, and -7.0 . Mean, maximum, and minimum average humidity ( $\%$ ) across periods were, respectively, 83,99 , and 65 , whereas no precipitation was observed.

\section{Sampling}

Samples of hay and DDGS were collected weekly, pooled across all weeks within each period, and analyzed for nutrient profile by a commercial laboratory (Dairy One Forage Laboratory, Ithaca, NY). All samples were analyzed by wet chemistry procedures for concentrations of crude protein (method 984.13; AOAC, 2006), acid detergent fiber (method 973.18 modified for use in an Ankom 200 fiber analyzer, Ankom Technology Corp., Fairport, NY; AOAC, 2006), and neutral detergent fiber (Van Soest et al., 1991; modified for use in an Ankom 200 fiber analyzer, Ankom Technology Corp.). Calculations for total digestible nutrients used the equations proposed by Weiss et al. (1992), whereas 
$\mathrm{NE}_{\mathrm{m}}$ and $\mathrm{NE}_{\mathrm{g}}$ were calculated with the equations proposed by the NRC (2000). Hay nutritional profile was (DM basis) 61\% TDN, 37\% NDF, 28\% ADF, $1.29 \mathrm{Mcal} / \mathrm{kg}$ of NEm, $0.72 \mathrm{Mcal} / \mathrm{kg}$ of $\mathrm{NEg}$, and $20.8 \%$ CP. Nutritional profile for DDGS was (DM basis) 84\% TDN, 30\% NDF, 12.9\% ADF, $2.17 \mathrm{Mcal} / \mathrm{kg}$ of $\mathrm{NEm}, 1.49 \mathrm{Mcal} / \mathrm{kg}$ of $\mathrm{NEg}$, and $33.8 \%$ CP. Heifers had free access to mineral mix (Cattleman's Choice; Performix Nutrition Systems, Nampa, ID), contained $14 \% \mathrm{Ca}, 10 \% \mathrm{P}, 16 \%$ $\mathrm{NaCl}, 1.5 \% \mathrm{Mg}, 3,200 \mathrm{mg} / \mathrm{kg}$ of $\mathrm{Cu}, 65 \mathrm{mg} / \mathrm{kg}$ of I, $900 \mathrm{mg} / \mathrm{kg}$ of $\mathrm{Mn}, 140 \mathrm{mg} / \mathrm{kg}$ of Se, $6,000 \mathrm{mg} / \mathrm{kg}$ of $\mathrm{Zn}, 136,000 \mathrm{IU} / \mathrm{kg}$ of vitamin A, 13,000 IU/kg of vitamin D3, and $50 \mathrm{IU} / \mathrm{kg}$ of vitamin $\mathrm{E}$.

Individual full BW was collected on day -6 and -5 , before (day 0 ) and after (day 1) treatment application, and on day 3, 6, 9, and 10 of each period. Individual BW collected on day 0 and 1 were used to evaluate BW loss associated with treatment administration. Average daily gain (ADG) was determined using heifer BW values obtained on day -6 and -5 (initial BW) and day 9 and 10 (final BW) of each experimental period. Dry matter intake (DMI) was evaluated daily from day -5 to 10 from each pen within each period by collecting and weighing nonconsumed feed. Heifer BW collected on day -6 and -5 of each period were averaged within pen and used to calculate intake as $\%$ of BW. Samples of the offered and nonconsumed hay were collected daily from each pen and dried for $96 \mathrm{~h}$ at $50{ }^{\circ} \mathrm{C}$ in forced-air ovens for dry matter calculation. Hay and total DMI of each pen were divided by the number of heifers within each pen and expressed as kg per heifer/day. Total BW gain and DMI from day -5 to 10 of each period were used for heifer G:F calculation.

Blood samples were collected on day $-5,0$ (before treatment application), 1 (immediately at the end of treatment application and before full access to feed and water), 3, 6, and 10 of each experimental period via jugular venipuncture into commercial blood collection tubes (Vacutainer, $10 \mathrm{~mL}$; Becton Dickinson, Franklin Lakes, NJ) containing or not freeze-dried sodium heparin for plasma and serum collection, respectively. Blood samples were collected prior to daily feeding. All blood samples were placed immediately on ice, centrifuged $\left(2,500 \times g\right.$ for $\left.30 \mathrm{~min} ; 4^{\circ} \mathrm{C}\right)$ for either plasma or serum harvest, and stored at $-80^{\circ} \mathrm{C}$ on the same day of collection.

Plasma samples were analyzed for cortisol (Immulite 1000; Siemens Medical Solutions Diagnostics, Los Angeles, CA), haptoglobin (Cooke and Arthington, 2013), and ceruloplasmin
(Demetriou et al., 1974) concentrations. Serum samples, however, were analyzed for NEFA concentration using a colorimetric kit (HR Series NEFA - 2; Wako Pure Chemical Industries Ltd. USA, Richmond, VA) with the modifications described by Pescara et al. (2010). The intra- and inter- assay CV were, respectively, 1.9 and 4.7 for haptoglobin, 4.1 and 8.6 for ceruloplasmin, and 4.4 and 5.9 for NEFA. Plasma cortisol was analyzed within a single assay, with an intra-assay CV of $0.9 \%$.

\section{Statistical Analysis}

Data were analyzed using the Mixed procedure of SAS (SAS Inst. Inc., Cary, NC), with pen as the experimental unit and Satterthwaite approximation to determine the denominator $\mathrm{df}$ for the tests of fixed effects. The model included fixed effects of treatment, day, and the resultant interaction, in addition to period and square as independent variables. Intake data were analyzed using day -5 to -2 averaged DMI as an independent covariate within each experimental period. Blood variables, however, were analyzed using values obtained on day -5 and 0 (before treatment application) of each experimental period as an independent covariate. Data were analyzed using pen and heifer(pen) as random variables, whereas for DMI pen was used as the random variable. The specified term for all repeated statements was day, with pen (treatment $\times$ period) as subject for DMI and heifer (pen $\times$ period $\times$ treatment) as subject for all other analyses. The covariance structure used was first-order autoregressive, which provided the smallest Akaike information criterion and hence the best fit for all variables analyzed. All results are reported as covariately-adjusted least square means. Significance was set at $P \leq 0.05$ and tendencies were determined if $P>0.05$ and $\leq 0.10$. Repeated measures are reported according to main treatment effect if the treatment $\times$ day interaction was $P>0.10$.

\section{RESULTS}

\section{Performance and Intake Variables}

A treatment effect was detected $(P<0.01)$ for $\mathrm{BW}$ loss from day 0 to 1 , being greater in WD, FWD, and FD compared with CON heifers, greater $(P<0.03)$ in FWD and FD compared with WD heifers, and similar $(P=0.64)$ among FWD and FD heifers (Table 1). Consequently, BW after treatment application (day 1$)$ was greater $(P<0.01)$ in $\mathrm{CON}$ 
Table 1. Performance of beef heifers subjected to 1) feed and water deprivation for $24 \mathrm{~h}$ (FWD), or 2) feed deprivation for $24 \mathrm{~h}$, but regular access to water (FD), or 3) water deprivation for $24 \mathrm{~h}$, but regular access to feed (WD), or 4) regular access to feed and water $(\mathrm{CON})^{1}$

\begin{tabular}{lccccrr}
\hline \hline Item & CON & FD & FWD & WD & SEM & $P$-value \\
\hline $\mathrm{BW}^{2}, \mathrm{~kg}$ & & & & & & 0.96 \\
Initial & 303 & 303 & 303 & 303 & 1.01 & 0.26 \\
Day 0 & 310 & 311 & 311 & 312 & 1.01 & $<0.01$ \\
Day 1 & $315^{\mathrm{a}}$ & $292^{\mathrm{b}}$ & $293^{\mathrm{b}}$ & $297^{\mathrm{c}}$ & 1.02 & 0.03 \\
Day 3 & $312^{\mathrm{a}}$ & $314^{\mathrm{ab}}$ & $313^{\mathrm{ab}}$ & $316^{\mathrm{b}}$ & 1.02 & 0.02 \\
Day 6 & $317^{\mathrm{a}}$ & $315^{\mathrm{b}}$ & $317^{\mathrm{a}}$ & $319^{\mathrm{a}}$ & 1.01 & 0.52 \\
Final & 322 & 323 & 322 & 324 & 1.01 & $<0.01$ \\
Body weight loss ${ }^{3}, \%$ & $-1.68^{\mathrm{a}}$ & $6.25^{\mathrm{b}}$ & $6.00^{\mathrm{b}}$ & $5.11^{\mathrm{c}}$ & 0.41 & 0.21 \\
$\mathrm{ADG}^{4}, \mathrm{~kg}^{\mathrm{b} g}$ & 1.25 & 1.23 & 1.23 & 1.36 & 0.05 & 0.34 \\
Feed efficiency $^{5}, \mathrm{~g} / \mathrm{kg}$ & 145 & 157 & 158 & 162 & 7 & \\
\hline
\end{tabular}

${ }^{\mathrm{a}-\mathrm{c}}$ Within rows, values with different superscripts differ $(P<0.05)$.

${ }^{1}$ Treatments were concurrently applied from day 0 to 1 . Upon completion of treatment application (day 1 ), all pens received the same diet offered before treatment application.

${ }^{2}$ Initial and final body weight was calculated using averaging values from day -6 and -5 and day 9 and 10 , respectively.

${ }^{3}$ Calculated using body weight data from day 0 to 1 follow treatment application.

${ }^{4}$ Calculated using initial (average day -6 and day -5 ) and final (average day 9 and day 10) heifer body weight within each experimental period.

${ }^{5}$ Calculated using total feed intake and body weight gain of each pen within each experimental unit.

heifers compared with WD, FWD, and FD, greater $(P<0.01)$ in WD compared with FWD and FD, and similar $(P=0.50)$ among FWD and FD heifers (Table 1). On day 3, CON were lighter $(P<0.01)$ compared with WD heifers, whereas BW was similar $(P>0.12)$ among CON, FD, and FWD. On day 6 , heifers assigned to FD were lighter $(P<0.02)$ compared with CON, FWD, and WD. Yet, final BW did not differ $(P>0.52)$ among treatments at the end of the experimental period (day 10). No treatment effects were detected $(P>0.21)$ for overall ADG and feed efficiency (Table 1).

As expected based on experimental design, hay and total DMI were greater $(P<0.01)$ in CON compared with FWD and FD heifers on day 0 (Fig. 1). However, hay and total DMI of WD heifers on day 0 were also less $(P<0.01)$ compared with $\mathrm{CON}$, but greater $(P<0.01)$ compared with FD and FWD heifers (Fig. 1). On day 1, feed intake was greater $(P<0.05)$ in FWD heifers compared with CON and WD, greater $(P=0.04)$ for FD vs. WD, and similar $(P>0.22)$ among FWD vs. FD and CON vs. WD. On day 2, feed intake was greater only $(P=0.03)$ in CON compared with FD heifers, and remained similar $(P>0.20)$ across all treatments from day 3 to 10.

\section{Blood Variables}

Treatment $\times$ day interactions were detected for plasma cortisol $(P<0.01)$, ceruloplasmin $(P<0.01)$, and serum NEFA $(P<0.01)$. Plasma cortisol concentrations were greater $(P<0.01)$ in
FD and FWD compared with CON and WD heifers on day 1 , and greater $(P<0.04)$ in FWD compared with CON and WD heifers on day 3 (Fig. 2). Moreover, FD heifers $(P<0.03)$ had greater cortisol concentration compared with CON, FWD, and WD heifers on day 6 and 10 (Fig. 2). Serum NEFA concentrations were greater $(P<0.01)$ in FD, FWD, and WD compared with CON heifers on day 1 , and greater $(P<0.01)$ in FD and FWD compared with WD on day 1 (Fig. 2). After realimentation and rehydration, serum NEFA concentrations decreased promptly for all nutrient deprived treatments with no differences $(P>0.32)$ observed beginning on day 3 (Fig. 2). Plasma ceruloplasmin concentrations were greater $(P<0.05)$ in FD and FWD compared with $\mathrm{CON}$ heifers on day 1, and similar $(P>0.32)$ among FD, FWD, and WD treatments on day 1 . Heifers assigned to FD also had greater $(P<0.04)$ plasma ceruloplasmin concentration on day 3 and 6 compared with $\mathrm{CON}$ and WD heifers, and on day $6(P<0.05)$ compared with FWD heifers (Fig. 3). No treatment $\times$ day interaction was detected $(P=0.53)$ for plasma haptoglobin concentration, but day effects were detected $(P<0.01)$ for this variable which increase for all nutrient deprived treatments on day 1 (Fig. 3).

\section{DISCUSSION}

Beef cattle are subjected to feed and water deprivation during routine management practices including weaning (Haley et al., 2005), road transport (Marques et al., 2012), and upon arrival 

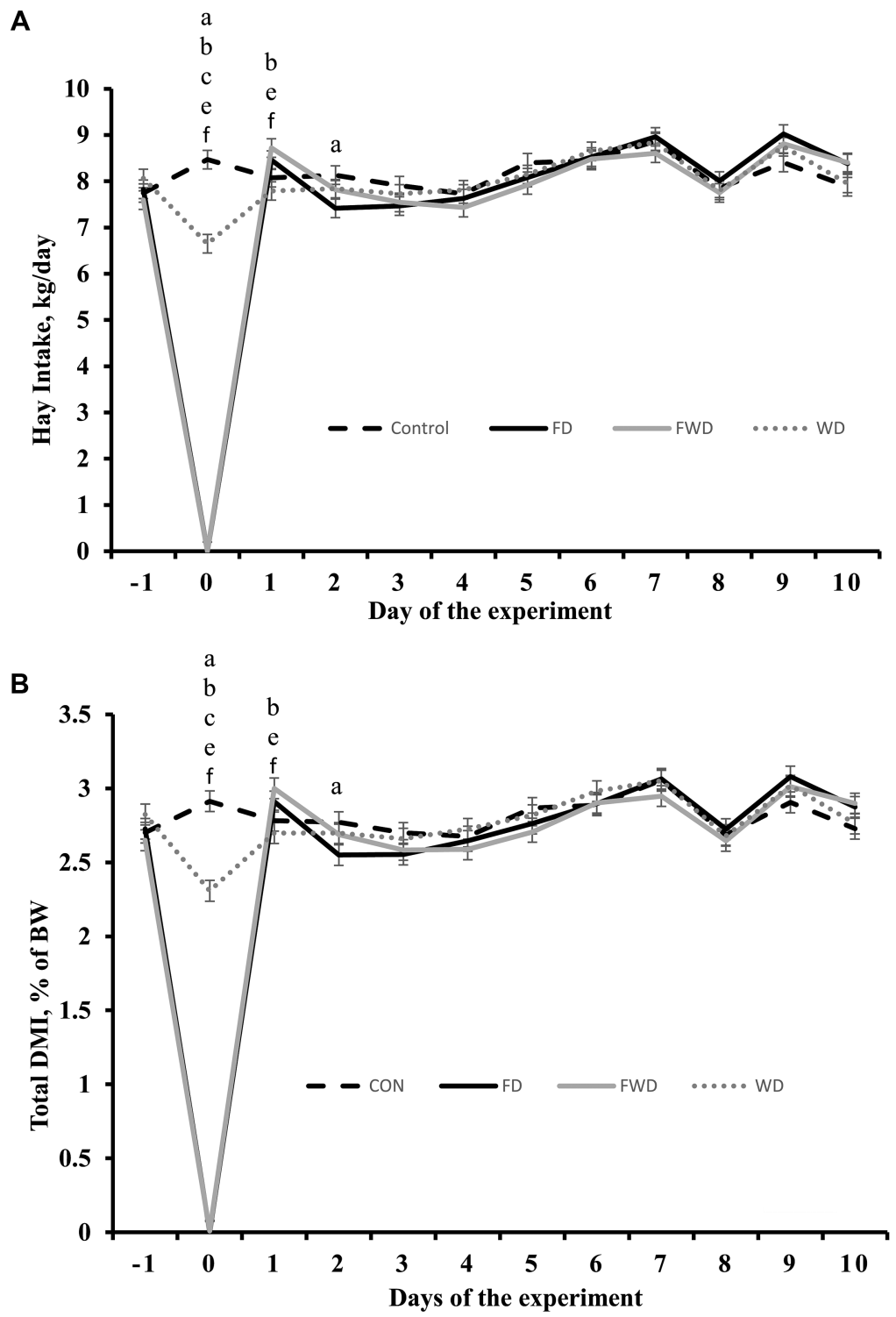

Figure 1. Hay intake (panel A) and total DMI (panel B) of beef heifers subjected to 1) feed and water deprivation for $24 \mathrm{~h}$ (FWD), or 2) feed deprivation for $24 \mathrm{~h}$, but regular access to water (FD), or 3) water deprivation for $24 \mathrm{~h}$, but regular access to feed (WD), or 4) regular access to feed and water $(\mathbf{C O N})$. Treatments were concurrently applied from day 0 to day 1. Upon completion of treatment application (day 1), all pens received the same diet offered before treatment application. Average of values obtained from day -5 to -2 were used as an independent covariate within each experimental period. Therefore, results reported are covariately-adjusted least square means. A treatment $\times$ day interaction was detected $(P<0.01)$. Within days, letters indicate the following treatment comparisons $(P \leq 0.05): \mathrm{a}=\mathrm{CON}$ vs. $\mathrm{FD}, \mathrm{b}=\mathrm{CON}$ vs. FWD, $\mathrm{c}=\mathrm{CON}$ vs. WD, $\mathrm{d}=\mathrm{FD}$ vs. FWD, e = FD vs. WD, and $\mathrm{f}=$ FWD vs. WD.

at a feedlot (Hutcheson and Cole, 1986; Loerch and Fluharty, 1999). Feed and water deprivation events, however, reduce feedlot-receiving performance (Marques et al., 2012), stimulate mobilization of body nutrients (Zhang et al., 2013a), and elicit an inflammatory response of feeder cattle (Cooke, 2017). For instance, feed and water deprivation during long transportation periods is a major contributor to the acute-phase response and reduced feedlot-receiving performance in beef cattle (Marques et al., 2012). Moreover, feeder cattle subjected to feed and water withdrawal often experience a BW loss (Phillips et al., 1991; Marques et al., 2012) and inconsistent feed intake for $2 \mathrm{wk}$ after feed and water deprivation event (Hutcheson and Cole, 1986; Zhang et al., 2013b), which in turn impact overall productivity of beef cattle. Water deprivation only has also a negative impact on cattle feed intake by reducing meal size in an attempt to regulate rumen homeostasis (Senn et al., 1996; Steiger Burgos et al., 2001). According to Steiger Burgos et al. (2001), dairy cows subjected to water restriction had reduced food intake, body weight, and meals size during water restriction period. However, these authors did not observe any sign of a compensatory increase in feed intake, which 

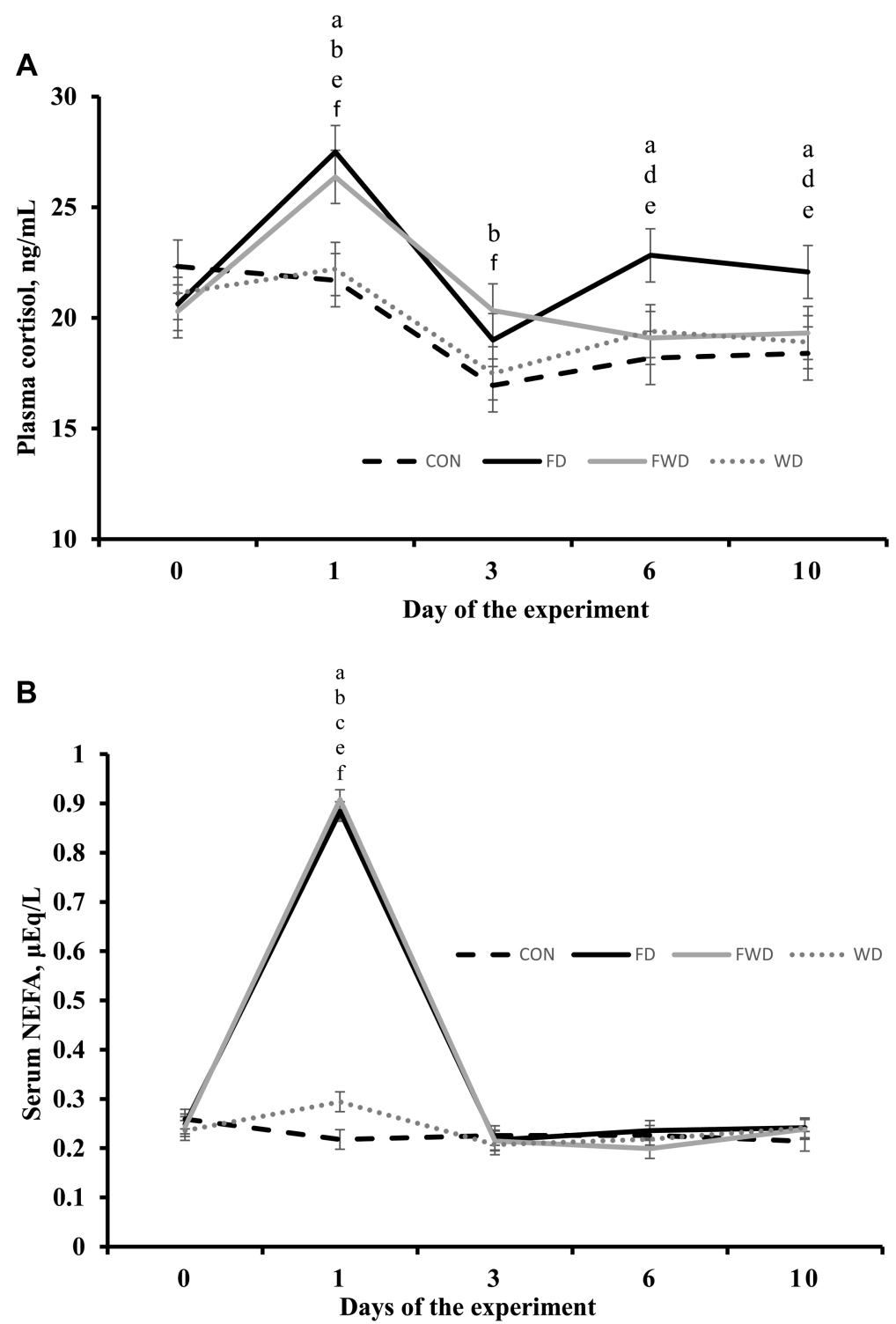

Figure 2. Plasma cortisol (panel A) and serum NEFA (panel B) concentration of beef heifers subjected to 1) feed and water deprivation for $24 \mathrm{~h}$ (FWD), or 2) feed deprivation for $24 \mathrm{~h}$, but regular access to water (FD), or 3) water deprivation for $24 \mathrm{~h}$, but regular access to feed (WD), or 4) regular access to feed and water $(\mathbf{C O N})$. Treatments were concurrently applied from day 0 to day 1. Upon completion of treatment application (day 1), all pens received the same diet offered before treatment application. Values obtained from day -5 were used as an independent covariate within each experimental period. Therefore, results reported are covariately-adjusted least square means. A treatment $\times$ day interaction was detected $(P<0.01)$. Within days, letters indicate the following treatment comparisons $(P \leq 0.05)$ : a $=$ CON vs. FD, $\mathrm{b}=\mathrm{CON}$ vs. FWD, $\mathrm{c}=\mathrm{CON}$ vs. WD, $\mathrm{d}=\mathrm{FD}$ vs. FWD, e $=$ FD vs. WD, and $\mathrm{f}=\mathrm{FWD}$ vs. WD.

returned to baseline levels after 3 to $4 \mathrm{~d}$ after water restriction event (Steiger Burgos et al., 2001). Yet, during the rehydration period, these authors also reported a greater and constant $\mathrm{BW}$ compared to baseline levels in dairy cows subjected to water restriction (Steiger Burgos et al., 2001). Senn et al. (1996) reported that lactating dairy cows had reduced feed intake by decreasing temporarily meal size, and a BW loss of approximately 12\% after $48 \mathrm{~h}$ of water deprivation.

In the current study, heifers lost approximately $5.7 \%$ of their BW due to deprivation of feed, water or both. Phillips et al. (1991) reported similar BW loss $(6.8 \%)$ to the current study after $48 \mathrm{~h}$ of feed and water deprivation and $60 \%$ of the total weight lost could be attributed to fecal and urinary excretion. Despite the difference in BW loss during treatment application herein, it was not sufficient to influence heifer BW and intake permanently, which returned to expected levels $3 \mathrm{~d}$ after nutrient deprivation. Accordingly, Phillips et al. (1991) also reported that steers subjected to 48 -h feed and water deprivation regained their weight lost within a 4-d period after free access to water and feed. Moreover, when dairy cows were water restricted for $48 \mathrm{~h}$ in Senn et al. (1996), the subsequent rehydration allowed an immediate restoration of BW. Contrary to the current study, Zhang et al. (2013b) demonstrated that 


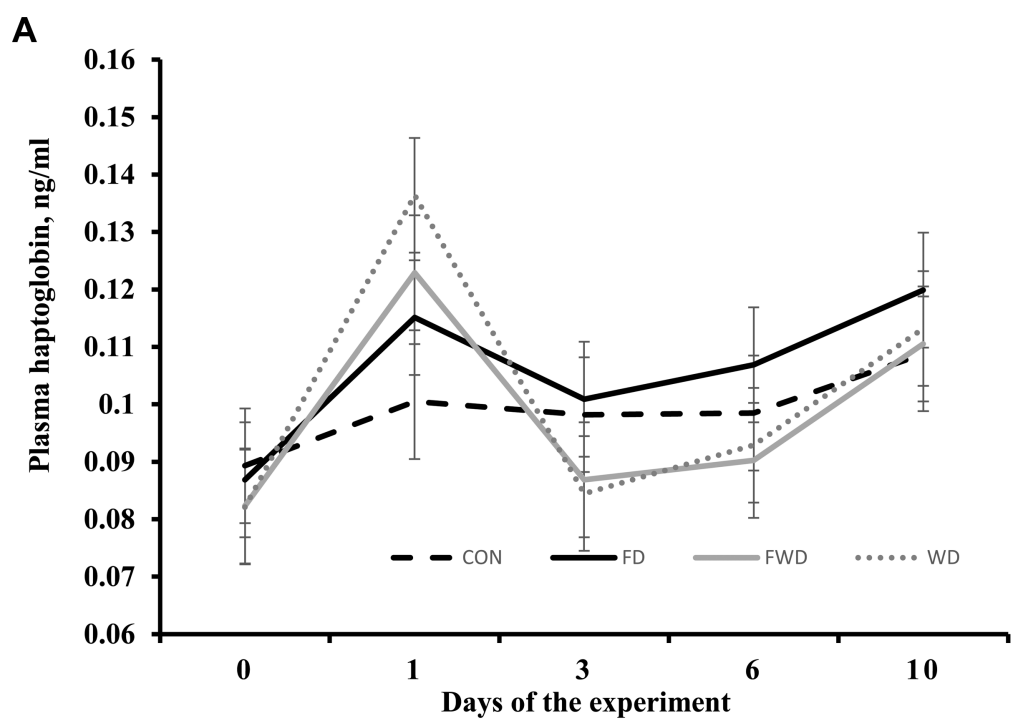

B

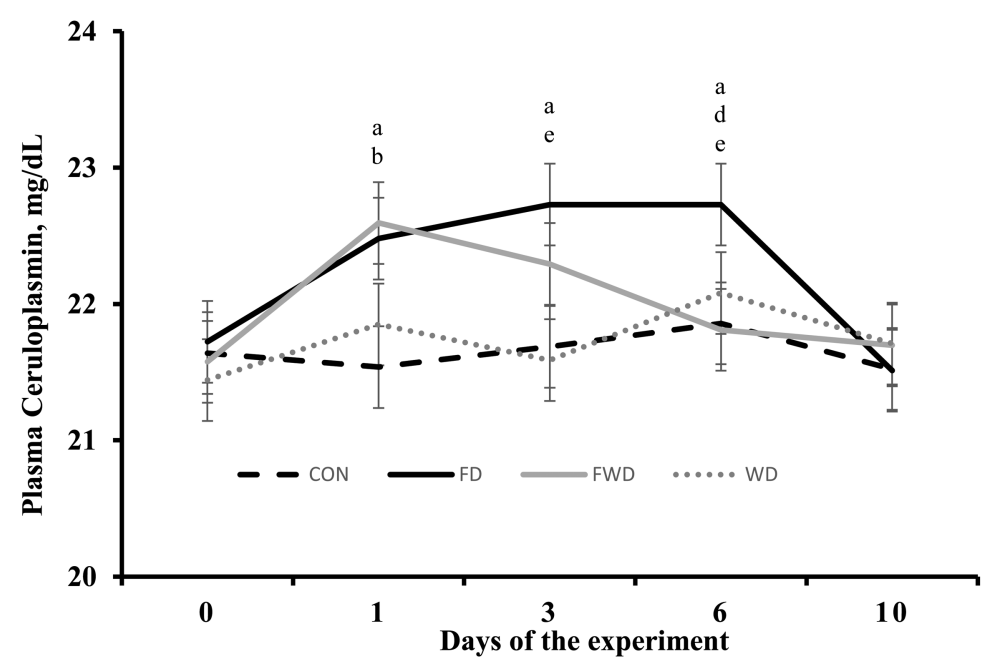

Figure 3. Plasma haptoglobin (panel A) and ceruloplasmin (panel B) concentration of beef heifers subjected to 1) feed and water deprivation for $24 \mathrm{~h}$ (FWD), or 2) feed deprivation for $24 \mathrm{~h}$, but regular access to water (FD), or 3) water deprivation for $24 \mathrm{~h}$, but regular access to feed (WD), or 4) regular access to feed and water $(\mathbf{C O N})$. Treatments were concurrently applied from day 0 to day 1 . Upon completion of treatment application (day 1), all pens received the same diet offered before treatment application. Values obtained from day -5 were used as an independent covariate within each experimental period. Therefore, results reported are covariately-adjusted least square means. A treatment $\times$ day interaction was detected $(P<0.01)$ for ceruloplasmin concentration. Within days, letters indicate the following treatment comparisons $(P \leq 0.05)$ : a $=C O N$ vs. $\mathrm{FD}, \mathrm{b}=\mathrm{CON}$ vs. FWD, $\mathrm{c}=\mathrm{CON}$ vs. WD, $\mathrm{d}=\mathrm{FD}$ vs. FWD, e $=\mathrm{FD}$ vs. WD, and $\mathrm{f}=\mathrm{FWD}$ vs. WD.

heifers restricted to $25 \%$ of their feed intake for 5 $\mathrm{d}$ required at least $2 \mathrm{wk}$ to return to expected feed intake. The differences between the present study and Zhang et al. (2013b) may be explained by the fact our heifers were subjected to $24 \mathrm{~h}$ of nutrient deprivation, whereas calves in Zhang's study had been restricted to $25 \%$ of their intake for $5 \mathrm{~d}$. The magnitude of the feed and water deprivation event is dependent upon the length and level of the restriction as well as the health and physiological status of the animal (Zhang et al., 2013a). Nevertheless, the mechanisms involved in controlling feed intake after a certain period of feed and water deprivation is unknown and deserves further investigation.
It is known, however, that feed intake in ruminants is controlled by a multifaceted mechanism involving the central nervous, neurochemical messaging, hormonal-cascade signaling, and physical responses of the gastrointestinal system (Allen et al., 2009; Sartin et al., 2011). However, during a feed and water deprivation event, ruminant metabolism promotes hunger and alter endocrine, metabolic and reproductive system to facilitate survival (Sartin et al., 2011). Accordingly, others studies demonstrated a neuroendocrine response as a result of elevated plasma cortisol concentration in cattle subjected to feed and water deprivation (Henricks et al., 1994; Marques et al., 2012). In the current 
study, FD and FWD treatments induced a greater plasma cortisol concentration compared with CON and WD after treatment application (day 1), but plasma cortisol concentrations remained elevated for a longer period in FD compared with $\mathrm{CON}$, WD, and FWD heifers. Feed and water deprivation also alter the nutritional status of the animal via mobilization of body reserves and increase circulating NEFA concentration in cattle (Henricks et al., 1994; Marques et al., 2012). Heifers subjected to nutrient deprivation herein also had increased circulating NEFA concentration compared with CON whereas NEFA concentration rapidly decreased when heifers had free access to water and feed. Water availability also appears to control, at least partially, feed intake in ruminants (Utley et al., 1970; Senn et al., 1996; Steiger Burgos et al., 2001). Similarly to the current study, Senn et al. (1996) reported that lactating dairy cows deprived of water for $48 \mathrm{~h}$ also had reduced feed intake due to a decrease in meal size during dehydration period, but no compensatory feed intake was observed during rehydration period.

Another mechanisms altered by nutrient deprivation and elevated circulating cortisol is the innate immune system, which in turn induce proinflammatory cytokines and acute-phase response in cattle (Murata et al., 2004; Marques et al., 2012; Cooke, 2017). Nonetheless, activation of this response, including circulating haptoglobin and ceruloplasmin, has been negatively associated with dry matter intake and ADG in cattle (Araujo et al., 2010). Nutrient deprivation event may also disturb the ruminal flora and cause microbial death (Meiske et al., 1958), resulting in the release of microbial endotoxins which could trigger an acutephase response (Carroll et al., 2009). According to Galyean et al. (1981), ruminal microbial concentration takes $72 \mathrm{~h}$ to return to its initial levels after feed and water deprivation, which can decrease ruminal fermentative capacity (Cole et al., 1986) and cattle intake (Cole and Hutcheson, 1985) after a feed and water deprivation event. Heifers utilized in this study were experiencing elevated plasma haptoglobin (day effect) and ceruloplasmin concentration after nutrient deprivation event, but plasma ceruloplasmin concentrations remained elevated for a longer period in heifers subjected to feed deprivation and full access to water (FD) for $24 \mathrm{~h}$. This last outcome could be attributed to increased circulating cortisol in FD heifers, given that cortisol is one of the main results of a neuroendocrine response, which also promotes a transitory nonspecific immune response (Carroll et al., 2009) and also to a ruminal flora imbalance and microbial death that cause release and absorption of microbial endotoxin (Meiske et al., 1958) which in turn could elicit an acute-phase response (Steiger et al. 1999; Carroll et al. 2009; Cooke et al., 2012), although ruminal parameters were not evaluated herein. The differences detected for blood variables herein, however, did not impact heifer performance and intake after $24 \mathrm{~h}$ of feed or water deprivation (Marques et al., 2012; Cooke, 2017).

In summary, our results indicate that feed or water deprivation for $24 \mathrm{~h}$ did not impact overall animal performance and intake, whereas blood variables result suggest that feed deprivation for $24 \mathrm{~h}$ with regular access to water is the major source of a neuroendocrine and acute-phase reaction, including elevated circulating cortisol, NEFA, and ceruloplasmin concentration in growing beef heifers. Nevertheless, additional research is warranted to further elucidate the mechanism involved in controlling feed intake after a period of feed and water deprivation as well as the neural, hormonal, and ruminal responses after a nutrient deprivation event in cattle.

\section{LITERATURE CITED}

Allen, M. S., B. J. Bradford, and M. Oba. 2009. Board invited review: the hepatic oxidation theory of the control of feed intake and its application to ruminants. J. Anim. Sci. 87:3317-3334. doi:10.2527/jas.2009-1779

AOAC. 2006. Official methods of analysis. 18th ed. Assoc. Off. Anal. Chem., Arlington, VA.

Araujo, D. B., R. F. Cooke, G. R. Hansen, C. R. Staples, and J. D. Arthington. 2010. Effects of rumen-protected polyunsaturated fatty acid supplementation on performance and physiological responses of growing cattle after transportation and feedlot entry. J. Anim. Sci. 88:4120-4132. doi:10.2527/jas.2009-2684

Carroll, J. A., R. R. Reuter, C. C. Chase, Jr, S. W. Coleman, D. G. Riley, D. E. Spiers, J. D. Arthington, and M. L. Galyean. 2009. Profile of the bovine acute-phase response following an intravenous bolus-dose lipopolysaccharide challenge. Innate Immun. 15:81-89. doi:10.1177/1753425908099170

Cole, N. A., and D. P. Hutcheson. 1985. Influence of prefast feed intake on recovery from feed and water deprivation by beef steers. J. Anim. Sci. 60:772-780. doi:10.2527/ jas1985.603772x

Cole, N. A., W. A. Phillips, and D. P. Hutcheson. 1986. The effect of pre-fast diet and transport on nitrogen metabolism of calves. J. Anim. Sci. 62:1719-1731. doi:10.2527/ jas1986.6261719x

Cooke, R. F. 2017. Invited paper: nutritional and management considerations for beef cattle experiencing stress-induced inflammation. Prof. Anim. Sci. 33:1-11. doi:10.15232/ pas.2016-01573

Cooke, R. F., and J. D. Arthington. 2013. Concentrations of haptoglobin in bovine plasma determined by ELISA or a colorimetric method based on peroxidase 
activity. J. Anim. Physiol. Anim. Nutr. (Berl). 97:531-536. doi:10.1111/j.1439-0396.2012.01298.x

Cooke, R. F., and D. W. Bohnert. 2011. Technical note: bovine acute-phase response after corticotrophin-release hormone challenge. J. Anim. Sci. 89:252-257. doi:10.2527/ jas.2010-3131

Cooke, R. F., J. D. Arthington, C. R. Staples, W. W. Thatcher, and G. C. Lamb. 2007. Effects of supplement type on performance, reproductive, and physiological responses of Brahman-crossbred females. J Anim. Sci. 85(10):2564-2574. doi:10.2527/jas.2006684

Cooke, R. F., J. A. Carroll, J. Dailey, B. I. Cappellozza, and D. W. Bohnert. 2012. Bovine acute-phase response after different doses of corticotropin-releasing hormone challenge. J. Anim. Sci. 90:2337-2344. doi:10.2527/jas. 2011-4608

Demetriou, J. A., P. A. Drewes, and J. B. Gin. 1974. Ceruloplasmin. In: Clinical chemistry: principles and techniques. 2nd ed. Harper and Row, Hagerstown, MD. p. $857-846$.

Galyean, M. L., R. W. Lee, and M. E. Hubbert. 1981. Influence of fasting and transit on ruminal and blood metabolites in beef steers. J. Anim. Sci. 53:7-18. doi:10.2527/ jas1981.5317

Haley, D. B., D. W. Bailey, and J. M. Stookey. 2005. The effects of weaning beef calves in two stages on their behavior and growth rate. J. Anim. Sci. 83:2205-2214. doi: $10.2527 / 2005.8392205 x$

Henricks, D. M., T. C. Jenkins, J. R. Ward, C. S. Krishnan, and L. Grimes. 1994. Endocrine responses and body composition changes during feed restriction and realimentation in young bulls. J. Anim. Sci. 72:2289-2297. doi:10.2527/1994.7292289x

Hutcheson, D. P., and N. A. Cole. 1986. Management of transit-stress syndrome in cattle: nutritional and environmental effects. J. Anim. Sci. 62:555-560.

Loerch, S. C., and F. L. Fluharty. 1999. Physiological changes and digestive capabilities of newly received feedlot cattle. J. Anim. Sci. 77:1113-1119.

Marques, R. S., R. F. Cooke, C. L. Francisco, and D. W. Bohnert. 2012. Effects of twenty-four hour transport or twenty-four hour feed and water deprivation on physiologic and performance responses of feeder cattle. J. Anim. Sci. 90:5040-5046. doi:10.2527/jas.2012-5425

Meiske, J. C., R. L. Salsbury, J. A. Hoefer, and R. W. Luecke. 1958. The effect of starvation and subsequent re-feeding on some activities of rumen microorganisms in vitro. $\mathbf{J}$. Anim. Sci. 17:774-781.

Murata, H., N. Shimada, and M. Yoshioka. 2004. Current research on acute phase proteins in veterinary diagnosis: an overview. Vet. J. 168:28-40. doi:10.1016/ S1090-0233(03)00119-9

NRC. 2000. Nutrient requirements of beef cattle. 7 th ed. Natl. Acad. Press, Washington, DC.
Pescara, J. B., J. A. Pires, and R. R. Grummer. 2010. Antilipolytic and lipolytic effects of administering free or ruminally protected nicotinic acid to feed-restricted Holstein cows. J. Dairy Sci. 93:5385-5396. doi:10.3168/ jds.2010-3402

Phillips, W. A., P. E. Juniewicz, and D. L. VonTungeln. 1991. The effect of fasting, transit plus fasting, and administration of adrenocorticotropic hormone on the source and amount of weight lost by feeder steers of different ages. J. Anim. Sci. 69:2342. doi:10.2527/1991.6962342x

Sartin, J. L., B. K. Whitlock, and J. A. Daniel. 2011. Triennial growth symposium: neural regulation of feed intake: modification by hormones, fasting, and disease. J. Anim. Sci. 89:1991-2003. doi:10.2527/jas.2010-3399

Senn, M., S. Gross-lüem, A. Kaufmann, and W. Langhans. 1996. Effect of water deprivation on eating patterns of lactating cows fed grass and corn pellets ad lib. Physiol. Behav. 48:1413-1418. doi:10.1016/S0031-9384(96)00304-6

Steiger, M., M. Senn, G. Altreuther, D. Werling, F. Sutter, M. Kreuzer, and W. Langhans. 1999. Effect of a prolonged low-dose lipopolysaccharide infusion on feed intake and metabolism in heifers. J. Anim. Sci. 77:25232532. doi:10.2527/1999.7792523x

Steiger Burgos, M., M. Senn, F. Sutter, M. Kreuzer, and W. Langhans. 2001. Effect of water restriction on feeding and metabolism in dairy cows. Am. J. Physiol. Regul. Integr. Comp. Physiol. 280:R418-R427. doi:10.1152/ ajpregu.2001.280.2.R418

Utley, P. R., N. W. Bradley, and J. A. Boling. 1970. Effect of restricted water intake on feed intake, nutrient digestibility and nitrogen metabolism in steers. J. Anim. Sci. 31:130 135. doi:10.2527/jas 1970.311130x

Van Soest, P. J., J. B. Robertson, and B. A. Lewis. 1991. Methods for dietary fiber, neutral detergent fiber, and nonstarch polysaccharides in relation to animal nutrition. J. Dairy Sci. 74:3583-3597. doi:10.3168/jds. S0022-0302(91)78551-2

Ward, J. R., D. M. Henricks, T. C. Jenkins, and W. C. Bridges. 1992. Serum hormone and metabolite concentrations in fasted young bulls and steers. Domest. Anim. Endocrinol. 9:97-103. doi:10.1016/0739-7240(92)90023-Q

Weiss, W. P., H. R. Conrad, and N. R. St. Pierre. 1992. A theoretically-based model for predicting total digestible nutrient values of forages and concentrates. Anim. Feed Sci. Technol. 39:95-110.

Zhang, S., R. I. Albornoz, J. R. Aschenbach, D. R. Barreda, and G. B. Penner. 2013a. Short-term feed restriction impairs the absorptive function of the reticulo-rumen and total tract barrier function in beef cattle. J. Anim. Sci. 91:1685-1695. doi:10.2527/jas.2012-5669

Zhang, S., J. R. Aschenbach, D. R. Barreda, and G. B. Penner. 2013b. Recovery of absorptive function of the reticulo-rumen and total tract barrier function in beef cattle after short-term feed restriction. J. Anim. Sci. 91:1696-1706. doi:10.2527/jas.2012-5774 